\section{Modeling Seasonal Dynamics of Canopy and Fruit Growth in Grapevine for Application in Trellis Tension Monitoring}

\author{
Julie M. Tarara ${ }^{1,6}$ and Paul E. Blom ${ }^{2}$ \\ USDA-ARS, Horticultural Crops Research Unit, 24106 North Bunn Road, \\ Prosser, WA 99350
}

\author{
Bahman Shafii ${ }^{3}$ and William J. Price ${ }^{4}$ \\ Statistical Programs, College of Agricultural and Life Sciences, University \\ of Idaho, Moscow, ID 83844
}

\section{Mercy A. Olmstead ${ }^{5}$ \\ Department of Horticulture \& Landscape Architecture, Washington State University, Prosser, WA 99350}

Additional index words. yield estimation, vegetative mass, fruit mass, thermal time logistic function, Vitis labruscana

\begin{abstract}
Estimates of canopy and fruit fresh mass are useful for more accurate interpretation of data from the Trellis Tension Monitor, a tool for real-time monitoring of plant growth and predicting yield in trellised crops. In grapevines (Vitis labruscana Bailey), measurements of shoot and fruit fresh mass were collected at frequent intervals (14 to 21 days) over 5 years, and these data were correlated with variables that could be obtained nondestructively: shoot length, number of leaves per shoot, and number of clusters per shoot. Shoot length provided a good estimator of shoot fresh mass in all years. Nonlinear logistic regression models described the dynamics of canopy growth from bloom to the early stages of ripening, which often is poorly represented by simple linear regression approaches to seasonal data. A generalized function indicated a lower bound of $\approx 600$ degree-days, after which an increase in shoot fresh mass could be considered on average to contribute only slightly to further increases in trellis wire tension. The dynamics of fruit mass were captured adequately by a nonlinear function, but not as well as vegetative mass because of larger variances in fruit mass. The number of clusters per shoot was associated with fruit mass only after the accumulation of $\approx 550$ degree-days or, equivalently, the time at which fruit mass exceeded $\approx 25 \mathrm{~g}$ per shoot. Seasonal dynamics of the ratio of fruit to vegetative fresh mass were not sufficiently discernable by the logistic models because of the dominance of fruit mass and its large interannual variation.
\end{abstract}

Recently, an approach was described for continuous monitoring of growth and estimating yield in grapevines or other trellised crops [Trellis Tension Monitor (TTM); Tarara et al., 2004, 2005]. Briefly, the technique involves continuous measurement of the tension in the primary horizontal support wire of the trellis.

Received for publication 8 Sept. 2008. Accepted for publication 18 Dec. 2008.

We thank R. Paul Schreiner for critical review.

Mention of a trademark, proprietary product, or vendor does not constitute a guarantee or warranty of the product by the U.S. Department of Agriculture and does not imply its approval to the exclusion of other products or vendors that also may be suitable.

${ }^{1}$ Research Horticulturist.

${ }^{2}$ Research Biologist.

${ }^{3}$ Director.

${ }^{4}$ Statistician

${ }^{5}$ Extension Specialist.

${ }^{6}$ To whom reprint requests should be addressed; e-mail jtarara@wsu.edu. structive sampling. However, the inherent sensitivity of the TTM to changes in the total mass being supported by the trellis wire (Tarara et al., 2004) highlights the need for nondestructive approaches to model building and verification. In general, there are well-recognized limitations to destructively sampling perennial plants, including its labor-intensive nature for large plants. These constraints reinforce the value of predictive models that can be verified by variables measured rapidly and nondestructively in the field (e.g., Castelan-Estrada et al., 2002; Montero et al., 2000)

Although canopy and fruit growth are nonlinear functions of time, they often are described using linear analyses (e.g., Rufat and DeJong, 2001; Williams et al., 1985) that may suffice for static point estimates (e.g., Castelan-Estrada et al., 2002). For dynamic modeling, such simplification can result in a poor representation of the data early or late in the season. Additionally, the relationship between reproductive and vegetative mass changes dynamically. The functionality of the TTM could be maximized with knowledge of the ratio of fruit to vegetative mass, which could be quantified throughout the growing season by direct measurement or modeling. Ultimately, with an extensive historical database, this information could be derived directly from trellis tension data. In either case, interpretation of the trellis tension trace and the accuracy of subsequent yield predictions could be improved. Realtime knowledge of the balance between fruit and canopy mass, defined as crop load, also can be applied to production decisions like fruit thinning or shoot thinning. Crop load is understood to influence a number of fruit quality components in grapevines (e.g., Edson et al., 1995; reviewed by Kliewer and Dokoozlian, 2005; Naor et al., 2002; Reynolds et al., 2005). The vegetative contribution to crop load commonly is quantified using leaf area (e.g., Edson et al., 1993; Reynolds et al., 2005) and previously we investigated its seasonal dynamics in grapevine (Blom and Tarara, 2007). Another commonly measured static variable, the mass of dormant cane prunings (e.g., Bennett et al., 2005; Naor et al., 2002), does not support real-time application of a technology like the TTM.

The objective of this study was to assess the dynamics of fruit and shoot fresh mass in grapevines trained to a single curtain, within and between seasons of a wide range, to develop functional relationships of expected responses to improve the potential for meaningful interpretation of TTM data in vineyards. Nonlinear regression analyses using logistic model forms were applied to produce average representations of canopy and fruit growth between about bloom and ripening, the period most important to application of the TTM for estimating yield. We also assessed the associations between direct measurements of plant fresh mass and a few select, easily measured variables that could be recorded nondestructively. 


\section{Materials and Methods}

Data were collected over 5 years (2002 to 2006 ) in a 0.34 -ha vineyard ( $V$. labruscana cv. Concord) near Prosser, WA (long. $46.30^{\circ}$ $\mathrm{N}$, lat. $119.75^{\circ} \mathrm{W}$ ), where the TTM simultaneously was developed. Destructive sampling was limited to the border rows of the 11-row plot to avoid midseason disturbance of the TTM systems that heavily instrumented the central nine rows of the vineyard. The plot was bordered to the west, about the direction of the prevailing wind, by several rows of Vitis spp. and to the east by fallow ground. The 'Concord' vines were planted in 1981 on their own roots and were grown with a single trunk trained to a bilateral cordon at $\approx 1.7 \mathrm{~m}$ aboveground. Vines were pruned annually to six- or seven-node spurs spaced 15 to $20 \mathrm{~cm}$ apart, the standard practice among juice grape growers in the area. The rows (95 to $105 \mathrm{~m}$ long) were oriented north-south with $3.0 \mathrm{~m}$ between rows and $2.4 \mathrm{~m}$ between vines within the row.

From 2001 to 2004, the block was managed under deficit irrigation to limit shoot growth for two purposes: 1) to limit the extent to which the change in trellis wire tension would be confounded between concurrent increases in fruit and vegetative mass; and 2) to demonstrate to local wine grape growers the potential applicability of the TTM under their standard irrigation practice. Analogous to that commercial practice, deficit irrigation was instituted after fruit set with soil water content $(\mathrm{v} / \mathrm{v})$ maintained between $11 \%$ and $14 \%$ by weekly irrigation. In 2005 , the vineyard was returned to a well-watered regimen, the local standard practice for juice grape production, with a target soil water content of $18 \%$ to $20 \%$. The soil was a Warden silt loam (coarse-silty, mixed, superactive mesic Xeric Haplocambid). Nominal field capacity was estimated as $23 \%$ and permanent wilting point as $7 \%$. Soil water content was measured weekly by neutron scattering (HydroProbe DR; Pacific Nuclear, Martinez, CA) in 0.3-m increments to $1.5 \mathrm{~m}$ in seven $(2002,2003)$ or 10 (2004 to 2006) access tubes spaced regularly across the vineyard.

Except in 2005 when labor constraints prematurely ended sampling, shoot and fruit growth were assessed at regular intervals (14 to $21 \mathrm{~d}$ ) from before bloom until 3 to 4 weeks before commercial maturity, the period most important for dynamic yield prediction. At each sampling date, 10 shoots were collected from each of four vines $(n=40)$ using a systematic protocol devised so that sample shoots represented the range of shoot lengths that were found in the vineyard at that date determined the previous day during the recording of nondestructive measurements of shoot length on a larger number of vines $(n=54)$. From the nondestructively recorded data, five equal categories of shoot length were set using the longest shoot on each vine to compute an upper bound. The destructive sample of 10 shoots per vine was comprised of two shoots in each length category selected on the basis of first encounter as the recorders worked systematically along the cordon from a randomly determined starting point. Samples included both "count" shoots (i.e., derived from a pruned spur position) and "noncount" shoots (i.e., derived from latent buds along the cordon). Shoots were excised from the spur or cordon, bagged, placed on ice, and transported to the laboratory for immediate measurement. For each shoot, the fresh mass of individual clusters (including rachis), leaves (including petiole), and stem (including tendrils) were recorded to the nearest $0.01 \mathrm{~g}$. Also measured were shoot length (SL) to the nearest $0.5 \mathrm{~cm}$, the number of leaves per shoot (LN), and the number of clusters per shoot. The direct measure of plant mass was regressed against those variables that could be recorded nondestructively (i.e., shoot length, number of leaves per shoot, number of clusters per shoot). Linear regres- sions were performed in SAS (Release 9.1; SAS Institute Inc., Cary, NC) using the REG procedure.

Thermal time, expressed as degree-days $\left(\mathrm{DD},{ }^{\circ} \mathrm{C}\right)$, was computed using a trapezoidal method of integration (Tobin et al., 2001) from 15-min average air temperatures (2-m reference height) obtained from the Washington State University Public Agricultural Weather System (now Agricultural Weather Network) station onsite (http://weather.wsu. edu/). Temperature accumulation was initiated on 1 Jan. using a $10^{\circ} \mathrm{C}$ lower threshold and no upper threshold. We departed from the local convention of initiating DD accumulation on 1 Apr. to standardize the temperature index and ensure the inclusion of budbreak regardless of seasonal variation in its calendar date. Fruit fresh mass per shoot, vegetative fresh mass per shoot, and the ratio of fruit to

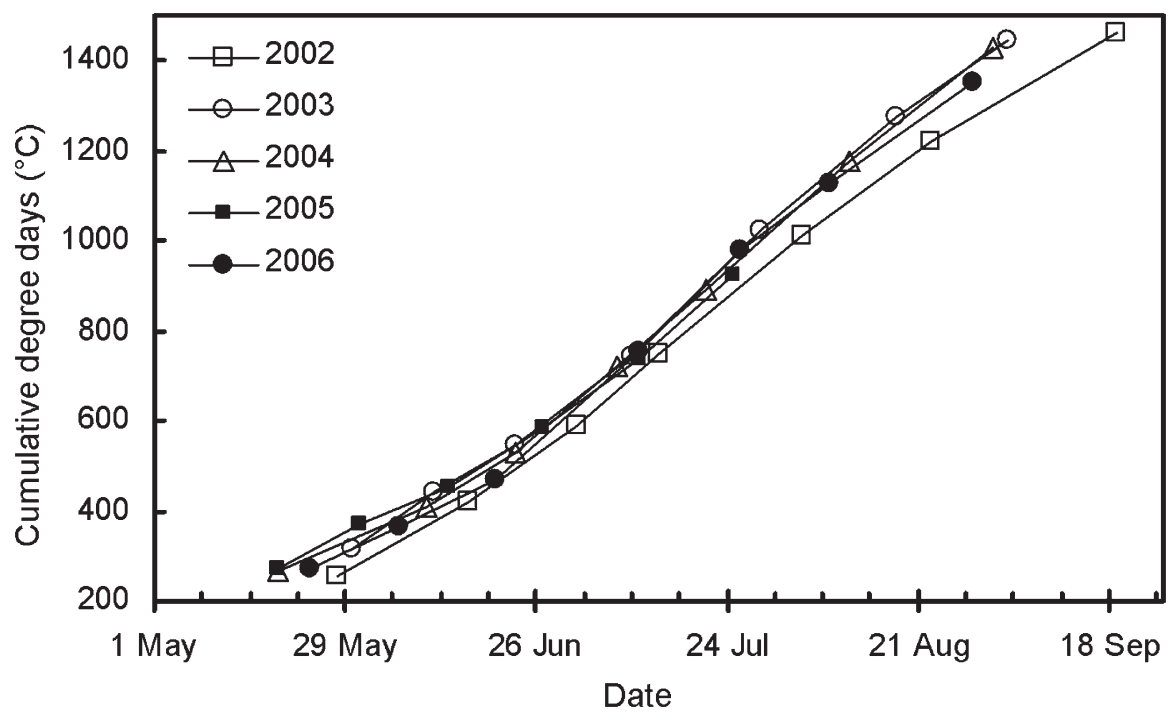

Fig. 1. Cumulative thermal time expressed as degree-days during the periods encompassing the sampling campaigns across five seasons. Symbols represent the calendar dates at which plant data were recorded. Lines are plotted to indicate trends from daily-derived temperature data.

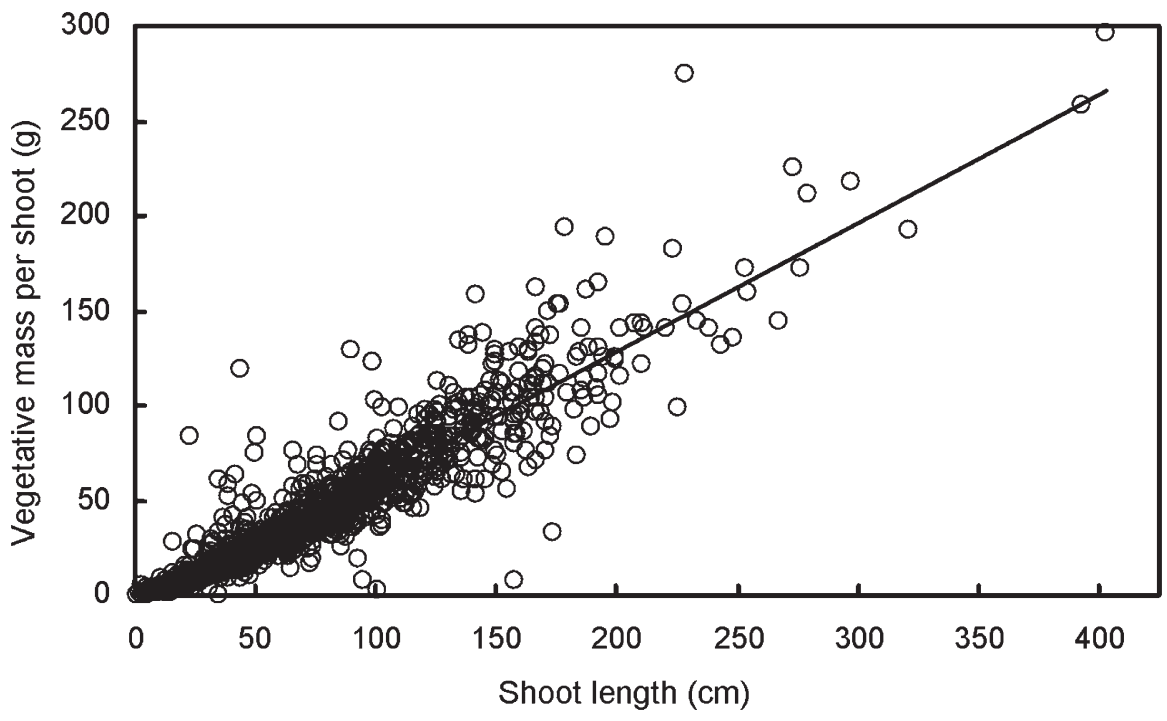

Fig. 2. Linear regression of vegetative mass per shoot as a function of shoot length. Symbols represent individual shoots. Data were pooled across years $\left(R^{2}=0.87\right.$; $\left.\mathrm{df}=1357\right)$. 
vegetative mass per shoot were fit as logistic functions of thermal time. The NLIN procedure (SAS, Release 9.1; SAS Institute Inc.) was used to estimate model parameters and associated statistics. The logistic model was expressed as:

$$
y=\frac{A}{1+\exp \left[-B\left(D D-D_{A}\right)\right]}
$$

where $\mathrm{A}$ is a theoretical maximum mass or ratio, $\mathrm{D}_{\mathrm{A}}$ is the number of DD required to reach $50 \%$ of $\mathrm{A}$, and $\mathrm{B}$ is the rate of increase either in mass or fruit:vegetative mass. A weighting function $\left(1 / s^{2}\right)$, where $s$ is the sample variance at a given $\mathrm{DD}$, was incorporated when heteroscedacity was evident in the model fits. The full data set $(n=1360)$ was used to construct the nonlinear models. The time at which the lower 95\% confidence limit of A occurred was estimated by rearranging Eq. [1] to solve for DD using estimated parameter values and y as the lower 95\% confidence limit of plant mass:

$$
D D=\frac{B D_{A}-\ln \left[-\frac{y-A}{y}\right]}{B}
$$

\section{Results and Discussion}

The 5 years were similar in rate of accumulation of DD during the measurement periods, except for a lower rate of accumulation in the latter half of 2002 (Fig. 1). This temperature anomaly coincided with the time at which berries were $\approx 7 \mathrm{~mm}$ in diameter, denoted as "pea size," and larger (approximately E-L stage 31+; Coombe, 1995). Approximately 3 additional weeks were required to accumulate 1400 DD during that year.

Pooled across years and sampling dates, there were strong linear associations between vegetative mass $\left(\mathrm{M}_{\mathrm{v}}\right)$ and shoot length $\left[\mathrm{M}_{\mathrm{v}}=\right.$ $(0.678 * \mathrm{SL})-7.250 ; R^{2}=0.87 ; \mathrm{df}=1357$; Fig. 2] and number of leaves per shoot $\left[\mathrm{M}_{\mathrm{v}}=\right.$ $(4.431 * \mathrm{LN})-8.308 ; R^{2}=0.83 ; \mathrm{df}=1357$; data not shown]. The relationship was improved by including both predictors in a firstorder linear model $\left[\mathrm{M}_{\mathrm{v}}=(0.418 * \mathrm{SL})+\right.$ $\left.(2.085 * \mathrm{LN})-12.056 ; R^{2}=0.92 ; \mathrm{df}=1356\right]$. Thus, simple linear relationships can be used throughout the season for point estimates of shoot fresh mass applied to further model building or validation, minimizing the need for destructive sampling. The TTM essentially is an indirect plant-mass meter, but because of the system's sensitivity to changes in plant mass that translate into changes in tension in the trellis wire (Tarara et al., 2004), there is a premium on variables that can be measured nondestructively, rapidly, and without redistributing the forces that impinge on the trellis wire.

The dynamics of canopy growth were well represented by logistic functions of thermal time that were fit individually to shoot length, number of leaves per shoot, and vegetative mass (Fig. 3). All parameters were significant with moderate correlations (Table 1). In nonlinear regression, any parameter correlation coefficient (r) less than 0.9 indicates a sufficient lack of redundancy in the model. Parameter $r$ values do not indicate model goodness of fit. As expected, each model describes a general growth curve, a process that slowly increases in rate, reaches a maximum rate of increase, then slows to approach a theoretical maximum value (A) at higher cumulative DD. Shoot length approached a theoretical maximum of $82 \mathrm{~cm}$ at a lower bound of $635 \mathrm{DD}(\approx 8$ to $13 \mathrm{July}$; Fig. 3A), whereas the number of leaves per shoot approached a theoretical maximum of 11.9 somewhat earlier [552 DD ( $\approx 27$ June to
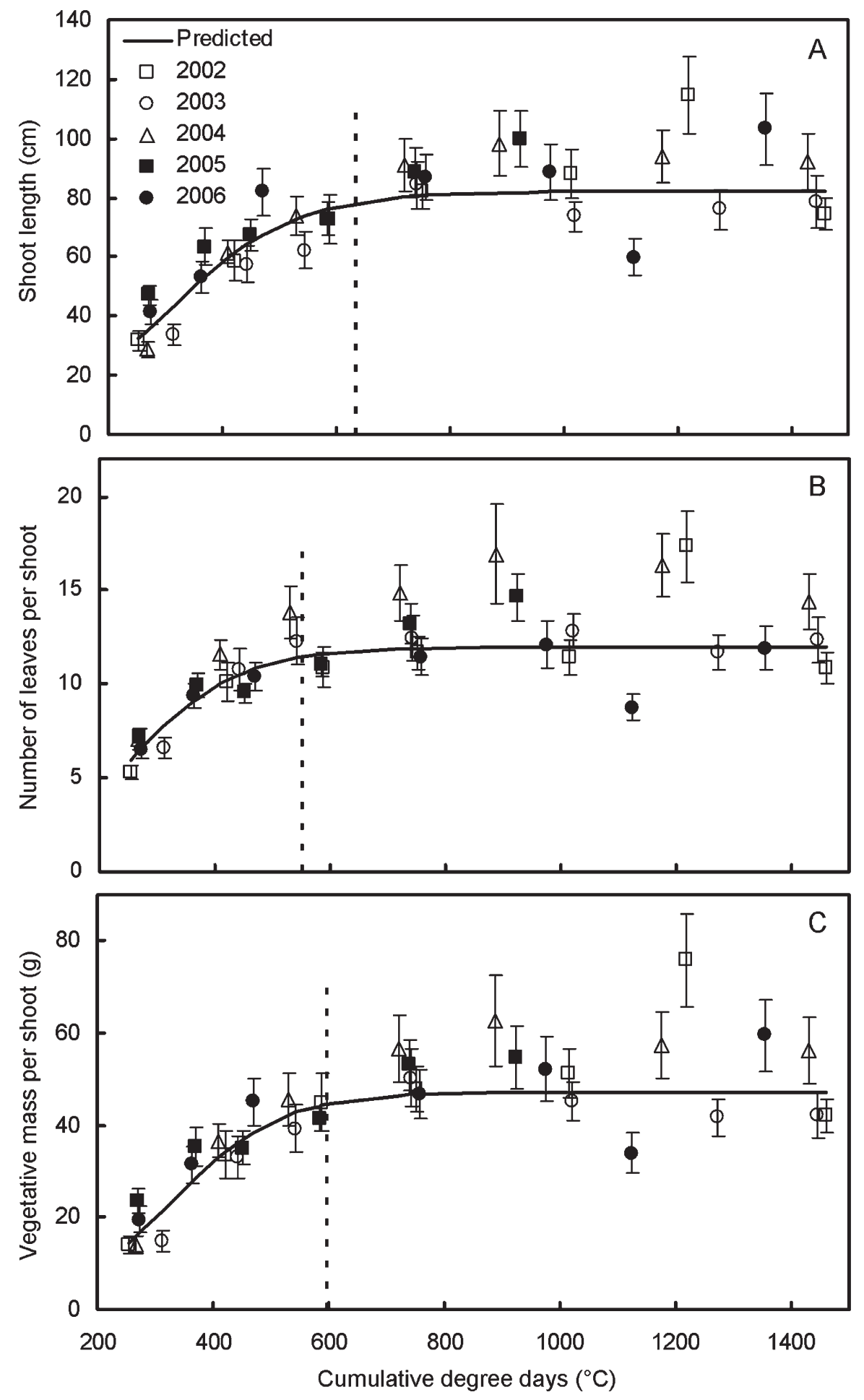

Fig. 3. Dynamic response of (A) shoot length, (B) number of leaves per shoot, and $(\mathbf{C})$ vegetative mass per shoot as functions of accumulated thermal time over five seasons. Symbols represent mean values at each sample date $( \pm \mathrm{SE})$. The predicted line results from a logistic fit to the data. The vertical bar in each panel indicates the lower bound on the thermal time at which the dependent variable was within $5 \%$ of the theoretical maximum value $[\approx 635$ degree-days (DD) for shoot length; $\approx 552$ DD for number of leaves; $\approx 598$ DD for vegetative mass]. 
Table 1. Logistic function parameter estimates used to characterize the dynamics of the measured variables.

\begin{tabular}{|c|c|c|c|c|c|c|c|}
\hline \multirow[b]{2}{*}{ Variable } & \multirow[b]{2}{*}{ Parameter $^{z}$} & \multirow[b]{2}{*}{ Parameter estimate } & \multirow[b]{2}{*}{ SE } & \multicolumn{2}{|c|}{$95 \%$ confidence limit } & \multicolumn{2}{|c|}{ Correlation matrix $^{\mathrm{y}}$} \\
\hline & & & & lower & upper & $\mathrm{B}$ & $\mathrm{D}$ \\
\hline \multirow[t]{3}{*}{ Vegetative mass } & $\mathrm{A}$ & 47.146 & 1.298 & 44.599 & 49.693 & -0.488 & 0.666 \\
\hline & $\mathrm{B}$ & 0.011 & 0.001 & 0.008 & 0.013 & & -0.519 \\
\hline & $\mathrm{D}$ & 330.306 & 10.398 & 309.908 & 350.704 & & \\
\hline \multirow[t]{3}{*}{ Shoot length } & A & 82.047 & 1.938 & 78.246 & 85.848 & -0.503 & 0.632 \\
\hline & B & 0.009 & 0.001 & 0.007 & 0.011 & & -0.238 \\
\hline & $\mathrm{D}$ & 300.560 & 9.244 & 282.426 & 318.693 & & \\
\hline \multirow[t]{3}{*}{ Number of leaves } & A & 11.953 & 0.254 & 11.454 & 12.452 & -0.535 & 0.381 \\
\hline & $\mathrm{B}$ & 0.011 & 0.001 & 0.008 & 0.013 & & 0.246 \\
\hline & $\mathrm{D}$ & 253.320 & 7.894 & 237.833 & 268.806 & & \\
\hline \multirow[t]{3}{*}{ Fruit mass } & A & 72.285 & 3.232 & 65.946 & 78.625 & -0.289 & 0.523 \\
\hline & $\mathrm{B}$ & 0.013 & 0.001 & 0.011 & 0.014 & & -0.903 \\
\hline & $\mathrm{D}$ & 599.100 & 14.695 & 570.300 & 627.900 & & \\
\hline \multirow[t]{3}{*}{ Fruit:vegetative mass } & A & 1.826 & 0.099 & 1.632 & 2.019 & -0.484 & 0.702 \\
\hline & B & 0.008 & 0.001 & 0.007 & 0.009 & & -0.919 \\
\hline & D & 673.000 & 23.641 & 626.600 & 719.400 & & \\
\hline
\end{tabular}

${ }^{\mathrm{z}}$ General form of the logistic function:

$$
y=\frac{A}{1+\exp \left[-B\left(D D-D_{A}\right)\right]}
$$

where $\mathrm{A}$ is a theoretical maximum mass or ratio, $\mathrm{D}_{\mathrm{A}}$ is the number of degree-days (DD) required to reach $50 \%$ of $\mathrm{A}$, and $\mathrm{B}$ is the rate of increase either in mass or in the ratio of fruit:vegetative mass.

y Parameter correlations, in which $r<0.9$ indicates a sufficient lack of redundancy in the model.

2 July); Fig. 3B]. The DD value at which the lower $95 \%$ confidence limit of A occurred for shoot mass represents an estimate of the average earliest thermal time at which additional canopy growth or an increase in vegetative mass would contribute negligibly to a detected increase in trellis tension. Over 5 years with a range of canopy characteristics, total vegetative mass per shoot increased rapidly up to $\approx 400 \mathrm{DD}$ with a theoretical maximum of $47.1 \mathrm{~g}$ occurring at $598 \mathrm{DD}$ ( $\approx 29$ June to 4 July; Fig. 3C). Thus, 600 DD defined the lower bound or approximately the earliest time at which one could expect subsequent changes in wire tension detected by a TTM to be attributable largely to fruit mass rather than to a combined increase in fruit and vegetative mass. This timeframe coincides with a lower bound on which real-time predictions of final yield begin to stabilize (unpublished data), indicating on average the earliest time at which growers could assign some confidence to yield predictions derived from trellis tension data. In eastern Washington state, this timing is $\approx 1$ month in advance of most growers' and processors' traditional hand sampling for yield estimation (B. Riley, Ste. Michelle Wine Estates, personal communication)

There were mixed results from associating various nondestructive, rapidly collected plant measures specifically to fruit mass, not unsurprising given variability in fruitfulness among shoots. Linear relationships between fruit mass per shoot and either shoot length $(\mathrm{r}=0.46)$ or number of leaves per shoot $(\mathrm{r}=$ 0.38 ) were not strong (data not shown). The inclusion of "noncount" shoots in the data set contributed substantially to this outcome. Number of clusters, a significant component of yield (e.g., Dami et al., 2006; Edson et al., 1993; Wolpert and Vilas, 1992), is the sole variable measured by some grape processors in predicting yields, which is a reasonable approach given that cluster number essentially is fixed early in the season (barring catastrophic disease incidence). Values of fruit mass per shoot as a function of cluster number per shoot appeared to fall into two populations; only after fruit mass per shoot exceeded $\approx 25 \mathrm{~g}$ was the number of clusters per shoot associated with total fruit mass $(r=$ 0.87; Fig. 4). That apparent discontinuity occurred consistently $\approx 530$ DD (range, 21 to 27 June), well after fruit set but before the berries were pea size. Earlier than that time, the number of clusters per shoot was poorly associated with fruit mass per shoot ( $\mathrm{r}=$ 0.14 ). This observation is inconclusive in indicating whether the number of clusters per shoot has independent usefulness for validation of temporal patterns in the trellis tension data. However, the observed dichotomy may be of consequence for grape processors who count clusters before bloom and associate cluster number with average berry or cluster masses recorded much later (e.g., 60 or $85 \mathrm{~d}$ postbloom), depending on the formulae used for predicting yield from these measures. If supplemental information on cluster mass is required, there are the attendant caveats about selective removal of mass in proximity to a TTM.

Considered comprehensively from fruit set to commercial maturity, grape berry growth (e.g., berry volume) typically is represented by a "double sigmoid curve" (e.g., Harris et al., 1968). We used a single sigmoidal function in this investigation because our sampling periods usually concluded early in the ripening period, the upper bound of the time most important to traditional yield estimation. A more extensive fresh mass data set collected through harvest would benefit from a more complex mixture model procedure (Price et al., 2008). Nonetheless, the simple sigmoidal function associated with the focused sampling period in this study may be useful as a remote indicator of the "lag" phase of berry development, an important trigger event for traditional yield estimation. The lag phase, defined by very low rates of berry growth before the onset of ripening, is used to time cluster sampling, particularly in wine grape vineyards. The original intent of the TTM specifically was dynamic yield estimation, the primary application of interest to the grape and wine industry. However, as a "plant-mass detector," the TTM also could be used to monitor phenology, real-time knowledge of which would supplement traditional yield estimation protocols.

Contrary to vegetative mass, the dynamics of fruit mass alone were not well described by the logistic fit (Fig. 5A; Table 1) primarily because of larger interannual variation in reproductive mass. The interannual variability in fruit mass that we observed is consistent with observations from other multiyear data sets (Dami et al., 2006). It is understood that suboptimal environmental conditions in short but critical periods may adversely affect reproductive development without substantial or lasting effect on vegetative growth in perennial fruit crops, including grapes (e.g., Esparza et al., 2001; Keller and Mills, 2007; McCarthy, 1997; Stephenson et al., 2003).

What remains unresolved is the proportion of the total seasonal change in trellis wire tension resulting from fruit rather than vegetation. Ideally, if one knew fruit:vegetative mass at any given time, the change in wire tension could be apportioned between reproductive and vegetative components, facilitating proportional adjustment of the dynamic yield estimate. Unlike the model for vegetative fresh mass alone, there was not a good fit for fruit:vegetative mass with a simple sigmoidal function (Fig. 5B; Table 1). The ratio approached its theoretical maximum value $\approx 928 \mathrm{DD}$ ( $\approx 27$ to 31 July) or sooner 


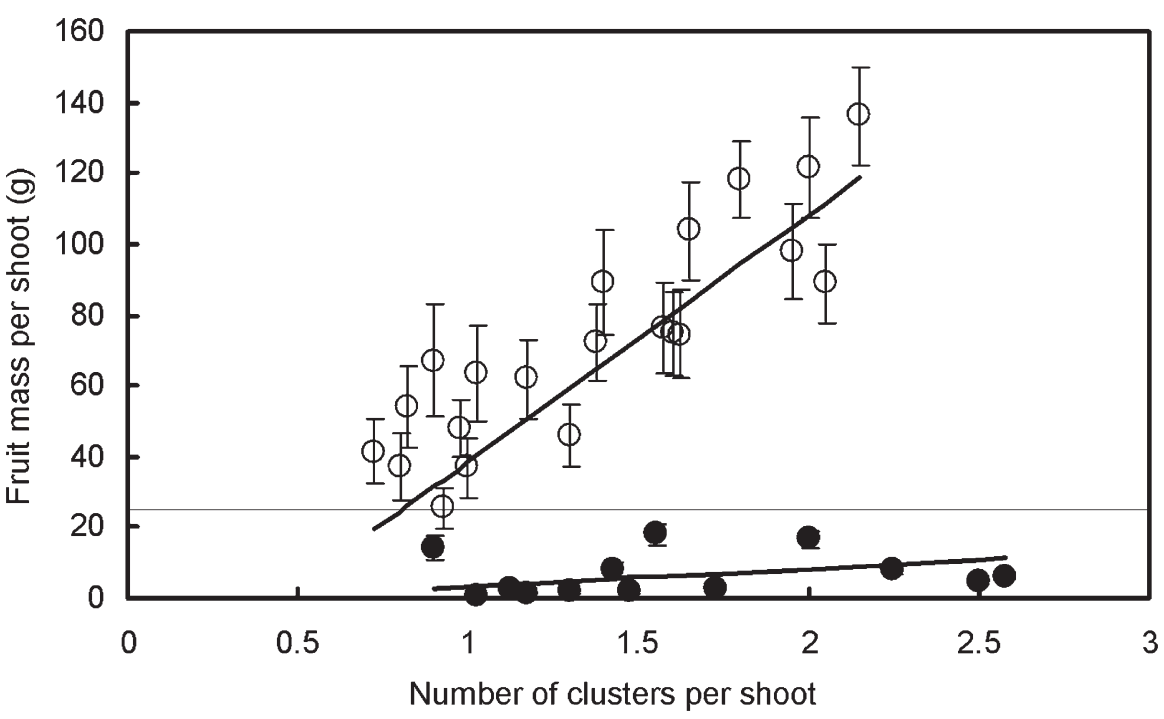

Fig. 4. Association between fruit mass per shoot and the number of clusters per shoot over five seasons. Symbols represent mean values at each sample date $( \pm \mathrm{SE})$. There are two distinct populations, the first (filled circles) before 550 degree-days (DD) and mean fruit mass per shoot less than $25 \mathrm{~g}(\mathrm{r}=0.14)$, the second (open circles) after $550 \mathrm{DD}$, and mean fruit mass per shoot greater than $25 \mathrm{~g}(\mathrm{r}=0.87)$.
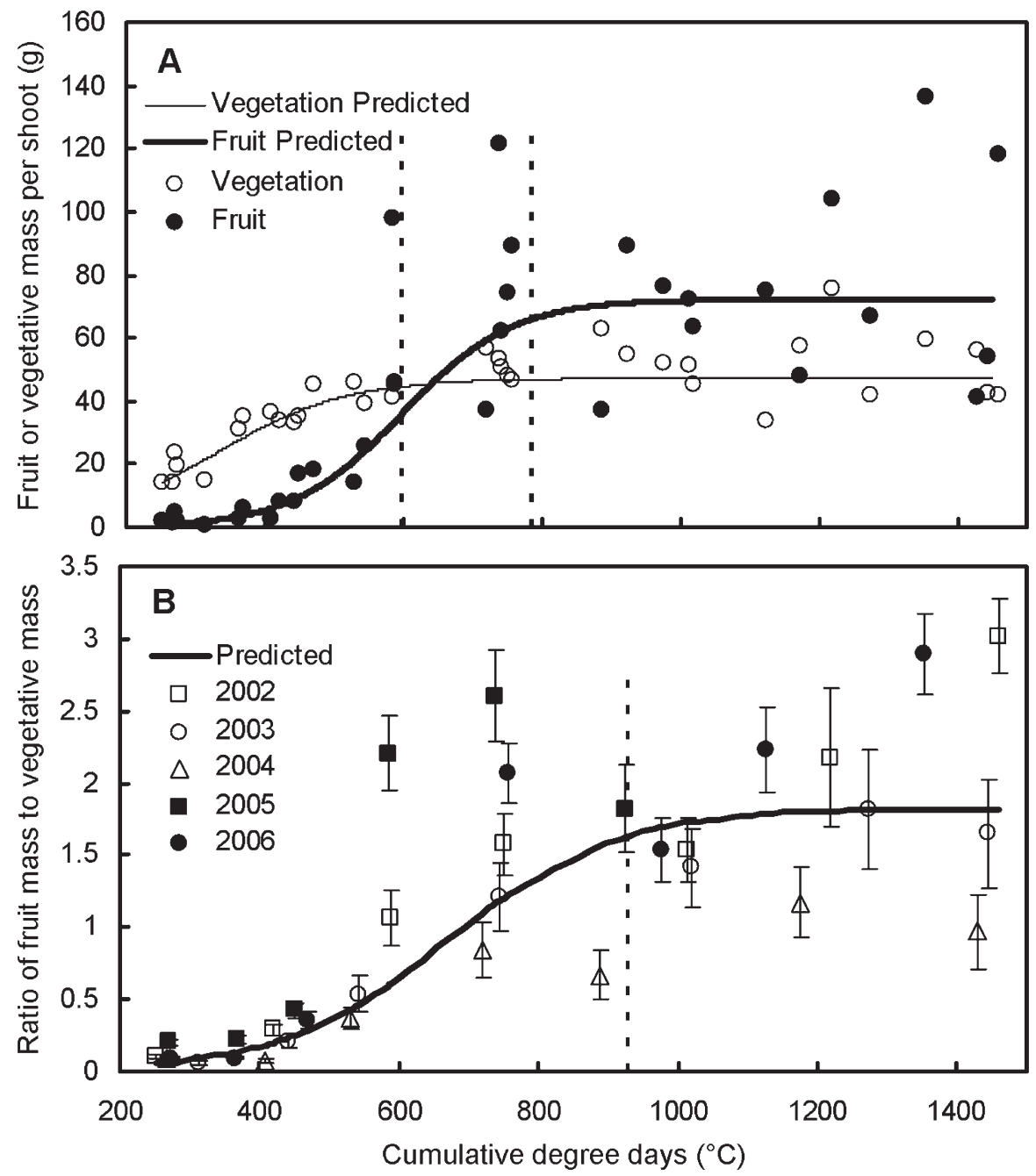

Fig. 5. Dynamic response of (A) fruit and vegetative mass per shoot and (B) the ratio of fruit to vegetative mass per shoot as a function of accumulated thermal time over five seasons. Symbols represent mean values at each sample date $( \pm \mathrm{SE}, \mathbf{B})$. The predicted line for fruit mass and fruit:vegetative mass results from a sigmoid fit to the data. The vertical bars indicate the thermal time at which the dependent variables were within $5 \%$ of their theoretical maximum values as estimated by the NLIN procedure [ $\approx 790$ degree-days (DD), fruit; $\approx 598$ DD, vegetation; $\approx 928$ DD, fruit:vegetation]. in all 5 years. Its lower bound occurred $\approx 2$ weeks before the average date of veraison (beginning of fruit ripening indicated by berry softening and color change) and as such may indicate the earliest expectation for the lag phase. The poor fit for fruit:vegetation appears to be driven by the large interannual variation in fruit mass, which makes it more difficult to model a single generalizable function either for fruit mass or fruit:vegetative mass. The fruit:vegetation outcome that we observed raises the likelihood of an insufficient description of expected behavior in a given year.

Reasonable caution should be taken against indiscriminate application of average expected responses. For example, an independent model for 2004 would have produced a consistently lower expected value of fruit mass and fruit:vegetative mass (Fig. 5B) than the mean prediction. The data from that year were indeed characterized by relatively high vegetative mass and low fruit mass in the aftermath of a cutworm (Noctuidae, possibly Amathes sp.) infestation around budbreak. Shoots that emerged subsequently from secondary and tertiary buds grew vigorously (most evident in number of leaves per shoot; Fig. 3B), a compensatory growth mechanism that has long been demonstrated in grapevines and other perennial fruit crops (e.g., Candolfi-Vasconcelos and Koblet, 1990; Edson et al., 1995; Petrie et al., 2000; Whiting and Lang, 2004). In grapes, secondary and tertiary buds are known to produce fewer and smaller clusters than do primary buds (Pratt, 1974).

The nonlinear models presented here were intended to encompass or characterize canopy or fruit over disparate years so that in the absence of an extensive historical database of tension curves, a generalized function can be applied in real time to the interpretation of trellis tension data (Fig. 6). The periods of greatest importance for such models are when canopy and fruit growth are concurrent and in advance of the traditional window for yield estimation (e.g., $60 \mathrm{~d}$ postbloom, lag phase). Described over the period encompassed by the destructive fruit and vegetation sampling (i.e., $\approx 250 \mathrm{DD}$ to 1400 DD), the typical TTM curve resembles a logistic function, slowly increasing in rate to a maximum rate. Two maximum tension values are approached, the first (Fig. 6) approximately coinciding with the theoretical maximum value for vegetative mass as modeled (Fig. 3C). A second dynamic maximum occurred after the sampling period for the present models, during the period of rapid berry enlargement before harvest (data not shown).

Although computationally intensive, nonlinear regression may be more valuable for real-time analyses because simple linear models appear insensitive to dynamic changes in rates of growth. The seasonal dynamics of leaf area were discussed previously (Blom and Tarara, 2007), in which a logistic function provided a better estimate of leaf area as a function of thermal time than did a linear model. Where seasonwide linear relationships 


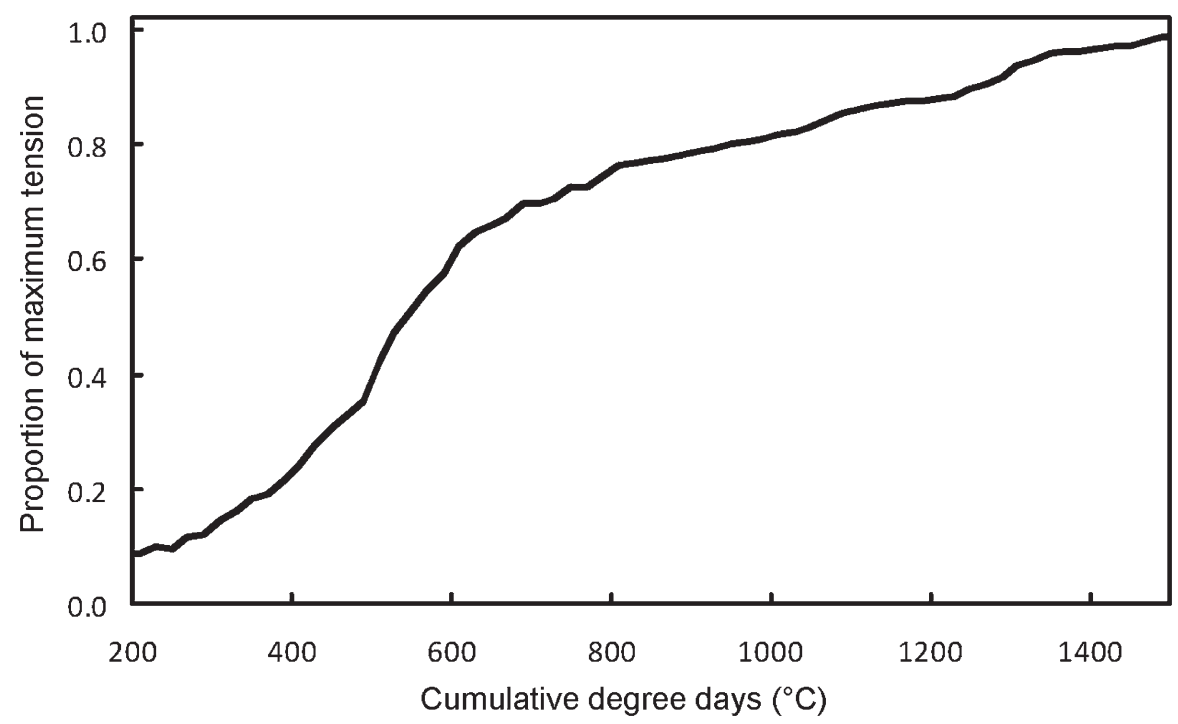

Fig. 6. Exemplary dynamic response of trellis wire tension during the period used for model development. Baseline tension value set before budbreak. Data were recorded in 2003. Line represents the mean of three Trellis Tension Monitors.

are adequate predictors, the preferred modeling approach will be directed by the ultimate application of the data (e.g., static estimates versus dynamic modeling) and the tolerance for error at given times during the growing season. Dynamic modeling is important for the TTM because of the information inherent in a dynamic estimate of the rate of canopy growth and the usefulness of upper and lower bounds on the functions' theoretical maximum values. Whether used for monitoring vine phenology or for real-time prediction of final yield, TTM data require dynamic interpretation rather than static or retrospective analyses at season's end. Logistic models of the dynamics of fresh mass can be made more robust with additional years' data and they can be developed for local calibration by compiling a database of the easily measured variables listed previously, namely shoot length and number of leaves per shoot. Despite variation in vine growth and our deliberate manipulation of midseason irrigation, the data set appears robust, at least in terms of vegetative fresh mass.

\section{Conclusion}

Continuous measurement of tension in the main support wire of a trellis is an indirect method of estimating the increase in crop mass during a growing season and, by extension, a means of predicting crop yield in real time. One variable that would increase this technology's accuracy in yield estimation is specifying the dynamic proportion of the increase in wire tension resulting from the current season's vegetative growth. Our observations over 5 years indicated that a lower bound on the increase in the vegetative contribution to total fresh mass was $\approx 600$ $\mathrm{DD}(\approx 8$ to 13 July at this location) and that the rate of increase in vegetative mass had dramatically declined within 2 to 3 weeks antecedent. Within-season dynamics can be described for vegetative mass per shoot estimated from one or a combination of easily obtained metrics, then fitting a nonlinear model as a function of thermal time. We suggest this approach because it is more sensitive to the dynamic period of shoot elongation and fruit enlargement and thus can be expected to produce more accurate estimates of changes in plant mass across the season. Our observations indicated that the seasonal dynamics of fruit mass up to ripening and fruit:vegetative mass may be too variable between years to apply a generalized function that decisively factors out the contribution of vegetation to the increase in total plant mass. The present data set incorporated seasons differing in thermal time, pest pressure, and irrigation management, and the results emphasize the importance of using local data for model parameterization. Although the fruit:vegetation mass relationship was not sufficient to apportion corresponding absolute values of tension within the TTM data, the consistency in the model of vegetative fresh mass suggests a baseline $(\approx 600$ DD) for adjusting within-season changes in trellis wire tension for clearer interannual comparison of yield estimates.

\section{Literature Cited}

Bennett, J., P. Jarvis, G.L. Creasy, and M.C.T. Trought. 2005. Influence of defoliation on overwintering carbohydrate reserves, return bloom, and yield of mature Chardonnay grapevines. Amer. J. Enol. Viticult. 56:386-393.

Blom, P.E. and J.M. Tarara. 2007. Rapid, nondestructive estimation of leaf area on fieldgrown Concord (Vitis labruscana) grapevines. Amer. J. Enol. Viticult. 58:393-397.

Candolfi-Vasconcelos, M.C. and W. Koblet. 1990. Yield, fruit quality, bud fertility and starch reserves of the wood as a function of leaf removal in Vitis vinifera-Evidence of compensation and stress recovering. Vitis 29:199-221.

Castelan-Estrada, M., P. Vivin, and J.P. Gaudillère. 2002. Allometric relationships to estimate sea- sonal above-ground vegetative and reproductive biomass of Vitis vinifera L. Ann. Bot. (Lond.) 89:401-408.

Coombe, B.G. 1995. Adoption of a system for identifying grapevine growth stages. Aust. J. Grape Wine Res. 1:100-110.

Dami, I., D. Ferree, A. Prajitna, and D. Scurlock. 2006. A five-year study on the effect of cluster thinning on yield and fruit composition of 'Chambourcin' grapevines. HortScience 41: 586-588.

Edson, C.E., G.S. Howell, and J.A. Flore. 1993. Influence of crop load on photosynthesis and dry matter partitioning of Seyval grapevines. I. Single leaf and whole vine response pre- and post-harvest. Amer. J. Enol. Viticult. 44:139147.

Edson, C.E., G.S. Howell, and J.A. Flore. 1995. Influence of crop load on photosynthesis and dry matter partitioning of Seyval grapevines. III. Seasonal changes in dry matter partitioning, vine morphology, yield, and fruit composition. Amer. J. Enol. Viticult. 46:478-485.

Esparza, G., T.M. DeJong, S.A. Weinbaum, and I. Klein. 2001. Effects of irrigation deprivation during the harvest period on yield determinants in mature almond trees. Tree Physiol. 21:10731079 .

Harris, J.M., P.E. Kriedemann, and J.V. Possingham 1968. Anatomical aspects of grape berry development. Vitis 7:106-119.

Keller, M. and L.J. Mills. 2007. Effect of pruning on recovery and productivity of cold-injured Merlot grapevines. Amer. J. Enol. Viticult. 58:351-357.

Kliewer, W.M. and N.K. Dokoozlian. 2005. Leaf area/crop weight ratios of grapevines: Influence on fruit composition and wine quality. Amer. J. Enol. Viticult. 56:170-181.

McCarthy, M.G. 1997. The effect of transient water deficit on berry development of cv. Shiraz (Vitis vinifera L.). Aust. J. Grape Wine Res. 3:102-108.

Montero, F.J., J.A. de Juan, A. Cuesta, and A. Brasa. 2000. Nondestructive methods to estimate leaf area in Vitis vinifera L. HortScience 35:696698.

Naor, A., Y. Gal, and B. Bravdo. 2002. Shoot and cluster thinning influence vegetative growth, fruit yield, and wine quality of 'Sauvignon blanc' grapevines. J. Amer. Soc. Hort. Sci. 127:628-634.

Petrie, P.R., M.C.T. Trought, and G.S. Howell. 2000. Growth and dry matter partitioning of Pinot noir (Vitis vinifera L.) in relation to leaf area and crop load. Aust. J. Grape Wine Res. 6:40-45.

Pratt, C. 1974. Vegetative anatomy of cultivated grape-A review. Amer. J. Enol. Viticult. 25:131-150.

Price, W.J., B. Shafii, P.E. Blom, J.M. Tarara, L.J. Sanchez, and N. Dokoozlian. 2008. Modeling seasonal wine grape development using a mixture technique. Proc. Kansas State Univ. Conf. Appl. Stat. Agr. (in press).

Reynolds, A.G., T. Molek, and C. De Savigny. 2005. Timing of shoot thinning in Vitis vinifera: Impacts on yield and fruit composition variables. Amer. J. Enol. Viticult. 56:343356.

Rufat, J. and T.M. DeJong. 2001. Estimating seasonal nitrogen dynamics in peach trees in response to nitrogen availability. Tree Physiol. 21:1133-1140.

Stephenson, R.A., E.C. Gallgher, and V.J. Doogan. 2003. Macadamia responses to mild water stress at different phenological stages. Aust. J. Agr. Res. 54:67-75. 
Tarara, J.M., J.C. Ferguson, P.E. Blom, M. Pitts, and F.J. Pierce. 2004. Estimation of grapevine crop mass and yield via automated measurements of trellis tension. Trans. ASAE 47:647-657.

Tarara, J.M., J.C. Ferguson, M. Pitts, F.J. Pierce, G. Hyde, and R.L. Wample. 2005. Apparatus and method for measuring the mass of vegetation or fruit supported on a trellis. U.S. Patent 6854337. Date issued 15 February.
Tobin, P.C., S. Nagarkatti, and M.C. Saunders. 2001. Modeling development in Grape Berry Moth (Lepidoptera: Tortricidae). Environ. Entomol. 30:692-699.

Whiting, M.D. and G.A. Lang. 2004. 'Bing' sweet cherry on the dwarfing rootstock 'Gisela 5', Thinning affects fruit quality and vegetative growth but not net $\mathrm{CO}_{2}$ exchange. J. Amer. Soc. Hort. Sci. 129:407-415.
Williams, D.W., L.E. Williams, W.W. Barnett, K.M. Kelley, and M.V. McKenry. 1985. Validation of a model for the growth and development of the Thompson Seedless grapevine. I. Vegetative growth and fruit yield. Amer. J. Enol. Viticult. 36:275-282.

Wolpert, J.A. and E.P. Vilas. 1992. Estimating vineyard yields: Introduction to a simple, twostep method. Amer. J. Enol. Viticult. 43:384-388. 